\title{
Does pulse pressure variation predict fluid responsiveness in critically ill patients? A systematic review and meta-analysis
}

\author{
Xiaobo Yang and Bin Du*
}

\begin{abstract}
Introduction: Fluid resuscitation is crucial in managing hemodynamically unstable patients. The last decade witnessed the use of pulse pressure variation (PPV) to predict fluid responsiveness. However, as far as we know, no systematic review and meta-analysis has been carried out to evaluate the value of PPV in predicting fluid responsiveness specifically upon patients admitted into intensive care units.

Methods: We searched MEDLINE and EMBASE and included clinical trials that evaluated the association between PPV and fluid responsiveness after fluid challenge in mechanically ventilated patients in intensive care units. Data were synthesized using an exact binomial rendition of the bivariate mixed-effects regression model modified for synthesis of diagnostic test data.

Result: Twenty-two studies with 807 mechanically ventilated patients with tidal volume more than $8 \mathrm{ml} / \mathrm{kg}$ and without spontaneous breathing and cardiac arrhythmia were included, and 465 were responders (58\%). The pooled sensitivity was 0.88 (95\% confidence interval (Cl) 0.81 to 0.92 ) and pooled specificity was 0.89 ( $95 \% \mathrm{Cl} 0.84$ to 0.92 ). A summary receiver operating characteristic curve yielded an area under the curve of 0.94 (95\% Cl 0.91 to 0.95 ). A significant threshold effect was identified.
\end{abstract}

Conclusions: PPV predicts fluid responsiveness accurately in mechanically ventilated patients with relative large tidal volume and without spontaneous breathing and cardiac arrhythmia.

\section{Introduction}

Despite the fact that fluid resuscitation is considered the first line of therapy in hemodynamically unstable patients [1], a large body of evidence indicates that unnecessary positive fluid balance is associated with increased morbidity and mortality [2-4]. Moreover, conflicting results have been reported with regards to studies investigating goaldirected hemodynamic therapy in critically ill patients, such as Rivers and colleagues' study and the OPTIMISE study [5,6]. No matter what the study result is, the first step in hemodynamic therapy in all of the above studies is always preload optimization. However, only about onehalf of the critically ill patients exhibit a positive response to fluid challenge [7], and accurate prediction of fluid

\footnotetext{
*Correspondence: dubin98@gmail.com

Medical ICU, Peking Union Medical College Hospital, Peking Union Medical College and Chinese Academy of Medical Sciences, 1 Shuai Fu Yuan, Beijing 100730, PR China
}

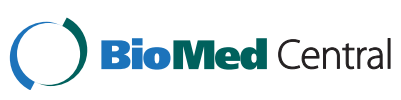

(c) 2014 Yang and Du; licensee BioMed Central Ltd. This is an Open Access article distributed under the terms of the Creative Commons Attribution License (http://creativecommons.org/licenses/by/4.0), which permits unrestricted use, distribution, and reproduction in any medium, provided the original work is properly credited. The Creative Commons Public Domain Dedication waiver (http://creativecommons.org/publicdomain/zero/1.0/) applies to the data made available in this article unless otherwise stated. responsiveness remains one of the most difficult tasks at the bedside in the ICU.

Medical history, clinical manifestations (such as skin turgor, blood pressure, pulse rate, and urine output), and routine laboratory tests are important but of limited sensitivity and specificity $[7,8]$. Static measures, including central venous pressure, pulmonary capillary wedge pressure, right ventricular end-diastolic volume, left ventricular end-diastolic area, inferior vena-caval diameter, and global end-diastolic volume index, are of poor value in guiding fluid resuscitation $[1,7,9]$.

Over the last decade, a number of studies have been reported, which have used heart-lung interactions during mechanical ventilation to assess fluid responsiveness. Among these functional hemodynamic parameters, pulse pressure variation (PPV) - which can easily and accurately obtained by online assessment of the arterial waveform with a standard multiparametric monitor [10] - has been shown to be highly predictive of fluid responsiveness in a 
systematic review, with sensitivity, specificity, and diagnostic odds ratio of $0.89,0.88$, and 59.86 , respectively [11]. Nevertheless, seven out of the 29 studies included in the systematic review were performed in operating rooms rather than ICUs. In addition, more studies have been published since. The objective of this systematic review and meta-analysis was to evaluate the accuracy of PPV in predicting fluid responsiveness in ICU patients.

\section{Materials and methods}

\section{Study selection and inclusion criteria}

All relevant clinical trials investigating the ability of PPV to predict fluid responsiveness in adult patients in the ICU were considered for inclusion. Only studies published as full-text articles in an indexed journal were included. Reviews, case reports, and studies published in abstract form were excluded. No language restriction was applied. No ethical approval and patient consent are required.

We included those studies in which the predictive value had been assessed by calculating both sensitivity and specificity in identifying those patients who subsequently responded to fluid challenge. We excluded studies employing a ventilatory strategy that maintained spontaneous breathing or generated a tidal volume $<8 \mathrm{ml} / \mathrm{kg}$. However, those studies without clear statement concerning the presence or absence of spontaneous breathing and tidal volume were included in the final analysis.

\section{Search strategy and data extraction}

Two authors independently performed a search in MEDLINE and EMBASE published from inception to 7 May 2014. If discrepancy existed between the two authors, it was resolved by discussion. An advanced search from the EMBASE website was used [12], with key words of pulse pressure (explode) and fluid responsiveness or fluid challenge or fluid resuscitation (explode). In addition to the electronic search, we checked out cross-references from original articles and reviews.

The two authors independently performed the initial selection by screening titles and abstracts. Citations were selected for further evaluation if the studies they referred to were studies investigating the predictive value of PPV in ICU adult patients. For detailed evaluation, we obtained peer-reviewed full texts of all possibly relevant studies. Data from each study were extracted independently using a standardized form, which included first author, year of publication, sample size, study setting, patient population, primary diagnosis, tidal volume, absence of spontaneous breathing or arrhythmia, type and amount of fluid infused, duration of fluid challenge, definition of responders, instrument(s) used for measuring index, and cardiac output. We also collected data about the method used to measure PPV as well as the threshold of PPV to achieve corresponding sensitivity and specificity. True positive, false positive, false negative, and true negative values were calculated to construct the $2 \times 2$ contingency table.

When two methods were compared, only the data of the reference method for measuring PPV were included. If data provided in the original study were inadequate to generate the contingency table, we sent two emails, at a 1-week interval, to the corresponding author for clarification. If the author failed to respond to our emails, we excluded the study from the final analysis.

\section{Quality assessment}

Study quality was assessed using the Quality Assessment of Diagnostic Accuracy included in Systematic Reviews (QUADAS-2) checklist [13], an improved, redesigned tool based both on experience using the original tool [14] and new evidence about sources of bias and variation in diagnostic accuracy studies. QUADAS-2 comprised four domains: patient selection, index test, reference standard, and flow and timing. Each domain was assessed in terms of risk of bias, and the first three domains were also assessed in terms of concerns regarding applicability. Each domain was scored as 'yes', 'no', or 'unclear'. We did not calculate summary scores because their interpretation was problematic and potentially misleading [15].

\section{Statistical analysis}

Data were synthesized using an exact binomial rendition of the bivariate mixed-effects regression model modified for synthesis of diagnostic test data [16-18]. Theoretically, bivariate models are motivated and allow estimation of the correlation of sensitivity and specificity, because, unlike univariate analyses, bivariate models do not transform pairs of sensitivity and specificity into single indicators as diagnostic accuracy [19]. The overall pooling of sensitivity, specificity, positive likelihood ratio, negative likelihood ratio, and diagnostic odds ratio was calculated using a random-effects model. Weighted summary receiver operating characteristic (SROC) analysis was implemented. The area under the curve (AUC) with 95\% confidence interval (CI) was calculated. Bayes nomogram was also constructed to show the diagnostic accuracy of PPV in prediction of fluid responsiveness.

Heterogeneity across studies was assessed using the chi-square test and the Cochran $Q$ statistic was calculated. The effect of heterogeneity was quantified using inconsistency $\left(I^{2}\right)$, which described the percentage of total variation attributed to heterogeneity rather than chance. $I^{2}>50 \%$ would mean significant heterogeneity [20]. A Galbraith plot was used to identify outliers. After removal of outliers, heterogeneity test was performed as mentioned before and AUC was also recalculated.

If significant heterogeneity was recorded, the proportion probably due to the threshold effect was evaluated 
using the Moses-Shapiro-Littenberg method [21]. Another potential source of heterogeneity was investigated by meta-regression analysis if heterogeneity among studies could not be fully explained by the threshold effect. Publication bias was investigated using Deeks' funnel plot asymmetry test and the $P$ value for the slope coefficient was reported [22].

A subgroup analysis was carried out on different types of fluid that were used to assess fluid responsiveness. For studies reporting both the predictive value of PPV and stroke volume variation (SVV), the SROC AUC was calculated for both parameters.

Data were analyzed using STATA version 13.0 (Stata Corp LP, College Station, TX, USA) with the MIDAS module. Most data are expressed as value $(95 \% \mathrm{CI})$. $P<0.05$ was considered statistically significant.

\section{Results}

The process of the study search and inclusion is summarized in Figure 1. The 22 studies included in the final meta-analysis enrolled a total of 807 patients, with an average of 37 patients per study [23-44].
Characteristics of the 22 included studies are summarized in Tables 1 and 2. A total of 465 patients (58\%) were responders to fluid challenge, ranging from 29 to $84 \%$ among 22 studies. Ten studies were performed in patients after cardiac surgery $(n=8)$ or other surgery $(n=2)$, while other studies were conducted in a mixed population of critically ill patients. Data on tidal volume, spontaneous breathing, and body weight were not available in some studies (Table 2). Most studies did not report the respiratory rate (Table 2). All of the included studies excluded patients with cardiac arrhythmia. With regards to fluid challenge, 6\% hydroxyethyl starch (HES) was most commonly used $(n=13)$, followed by crystalloids $(n=6)$, other colloids $(n=2)$, and blood $(n=1)$. A volume ranging from $100 \mathrm{ml}$ to $20 \mathrm{ml} / \mathrm{kg}$ body weight was infused within 1 minute up to 90 minutes. Cardiac output was monitored by means of PiCCO technology $(n=7)$, pulmonary artery catheter $(n=6)$, transesophageal/transthoracic echocardiography or Doppler measurements $(n=5)$, and other methods $(n=4)$. All studies except for two $[24,26]$ defined responders as patients whose stroke volume or cardiac output was increased by $\geq 15 \%$.

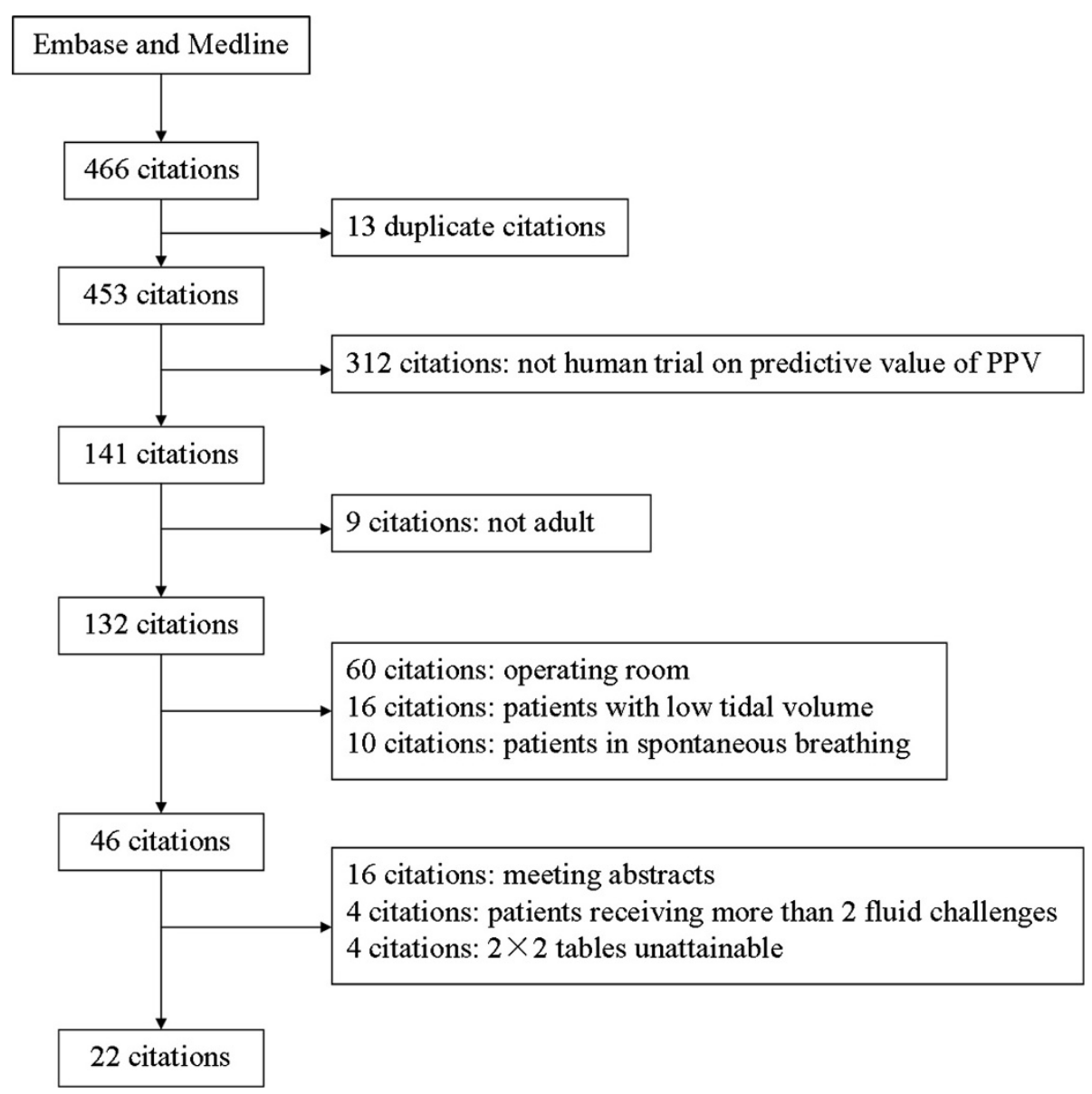

Figure 1 Flowchart of study selection. PPV, pulse pressure variation. 
Table 1 Selected spectrum characteristics of included studies

\begin{tabular}{|c|c|c|c|c|c|c|}
\hline Order & Authors & Year & Sample size & Setting & Admission & Diagnosis \\
\hline 1 & Michard and colleagues [23] & 2000 & 40 & $\mathrm{ICU}$ & Medical & Sepsis/septic shock \\
\hline 2 & Kramer and colleagues [24] & 2004 & 21 & SICU & Surgical & Cardiac surgery \\
\hline 3 & Feissel and colleagues [25] & 2005 & $20^{\mathrm{a}}$ & $\mathrm{ICU}$ & Medical & Sepsis/septic shock \\
\hline 4 & Charron and colleagues [26] & 2006 & 21 & $\mathrm{ICU}$ & NA & NA \\
\hline 5 & Monnet and colleagues [27] & 2006 & 30 & $\mathrm{MICU}$ & Medical & Shock \\
\hline 6 & Feissel and colleagues [28] & 2007 & $23^{b}$ & MICU & Medical & Sepsis/septic shock \\
\hline 7 & Wyffels and colleagues [29] & 2007 & 32 & $\mathrm{ICU}$ & Surgical & Cardiac surgery \\
\hline 8 & Auler and colleagues [30] & 2008 & 59 & SICU & Surgical & Cardiac surgery \\
\hline 9 & Monge Garcia and colleagues [31] & 2009 & 38 & $\mathrm{ICU}$ & NA & Shock \\
\hline 10 & Vistisen and colleagues [32] & 2009 & 23 & SICU & Surgical & Cardiac surgery \\
\hline 11 & Loupec and colleagues [33] & 2011 & 40 & SICU & Surgical and medical & Surgery and septic shock \\
\hline 12 & Biais and colleagues [34] & 2012 & 35 & SICU & Surgical and medical & Vascular surgery, trauma, septic shock \\
\hline 13 & Cecconi and colleagues [35] & 2012 & 31 & $\mathrm{ICU}$ & Surgical & High-risk surgery \\
\hline 14 & Fellahi and colleagues [36] & 2012 & 25 & SICU & Surgical & Cardiac surgery \\
\hline 15 & Khwannimit and colleagues [37] & 2012 & 42 & MICU & Medical & Sepsis/septic shock \\
\hline 16 & Monnet and colleagues [38] & 2012 & 26 & MICU & Medical & Shock \\
\hline 17 & Monnet and colleagues [39] & 2012 & 39 & MICU & Medical & Shock \\
\hline 18 & Yazigi and colleagues [40] & 2012 & 60 & SICU & Surgical & Cardiac surgery \\
\hline 19 & Fischer and colleagues [41] & 2013 & 37 & SICU & Surgical & Cardiac surgery \\
\hline 20 & Fischer and colleagues [42] & 2013 & 80 & SICU & Surgical & Cardiac surgery \\
\hline 21 & Ishihara and colleagues [43] & 2013 & 43 & $\mathrm{ICU}$ & Surgical & Noncardiac surgery \\
\hline 22 & Monnet and colleagues [44] & 2013 & 35 & MICU & Medical & Shock \\
\hline
\end{tabular}

MICU, medical intensive care unit; NA, not available; SICU, surgical intensive care unit. ${ }^{2}$ Twenty-two fluid challenges included. ${ }^{\text {'T }}$ wenty-eight fluid challenges included.

Overall, the methodological quality was moderate (Additional file 1). Specifically, five out of 22 included studies reported enrollment of consecutive patients, and four studies reported no test review bias; that is, interpretation of the reference standard results without knowledge of the result of the index test, and vice versa.

The results for the diagnostic performance of the included studies and the method used to measure PPV are presented in Table 3. The median threshold of PPV in predicting fluid responsiveness was $12 \%$ (interquartile range 10 to $13 \%)$.

Pooled sensitivity was 0.88 (95\% CI $=0.81$ to 0.92$)$ and pooled specificity was $0.89(95 \% \mathrm{CI}=0.84$ to 0.92$)$ (Figure 2). PPV had an overall positive likelihood ratio of $7.7(95 \% \mathrm{CI}=5.3$ to 11.3$)$, a negative likelihood ratio of 0.14 ( $95 \% \mathrm{CI}=0.08$ to 0.23 ), and a diagnostic odds ratio of $56(95 \% \mathrm{CI}=26$ to 122$)$. The SROC AUC was 0.94 ( $95 \% \mathrm{CI}=0.91$ to 0.95 ) (Figure 3 ).

Moderate heterogeneity existed among the studies, with Cochran $Q$ statistic of $4.681(P=0.042)$ and overall $I^{2}$ for bivariate model of $60 \%$ (95\% CI $=9$ to 100). All of the heterogeneity $(100 \%)$ was caused by the threshold effect. As a result, meta-regression analysis with the objective to explore the effects of potential covariates on the diagnostic performance of PPV was not performed. Four outliers were identified by means of a Galbraith plot (Figure 4) [30,41-43]. Heterogeneity became nonsignificant (Cochrane $Q$ statistic $=0.146, P=0.465$ ) after removal of these four outliers, while the SROC AUC slightly improved $(0.95,95 \% \mathrm{CI}=0.93$ to 0.97$)$.

We did not identify publication bias by Deeks' regression test of asymmetry; a statistically nonsignificant $P$ value of 0.41 for the slope coefficient suggested symmetry in the data and a low likelihood of publication bias (Figure 5). Bayes nomogram showed moderate fine likelihood ratios and post-test probabilities (Figure 6).

For studies using HES or saline to assess fluid responsiveness, the SROC AUC of PPV was $0.92(95 \% \mathrm{CI}=0.89$ to 0.94 ) and 0.96 (95\% CI $=0.94$ to 0.98$)$, respectively. Nine studies reported the predictive value of both PPV and SVV, and both SROC AUCs were $0.90(95 \% \mathrm{CI}=0.87$ to 0.93 ) (Additional file 2).

\section{Discussion}

The major finding of this systematic review and metaanalysis is that PPV during controlled mechanical ventilation 
Table 2 Selected methodological characteristics of included studies

\begin{tabular}{|c|c|c|c|c|c|c|c|c|c|c|c|c|c|}
\hline Order & Authors & Year & $\mathrm{Vt}(\mathrm{ml} / \mathrm{kg})$ & Body weight & $\begin{array}{l}\text { Spontaneous } \\
\text { breathing }\end{array}$ & $\begin{array}{l}\text { Respiratory rate } \\
\text { (times/minute) }\end{array}$ & $\begin{array}{l}\text { Cardiac } \\
\text { arrhythmia }\end{array}$ & $\begin{array}{l}\text { Infusion } \\
\text { fluid }\end{array}$ & $\begin{array}{l}\text { Infusion } \\
\text { volume }\end{array}$ & $\begin{array}{l}\text { Infusion time } \\
\text { (minutes) }\end{array}$ & Indices & $\begin{array}{l}\text { Method for } \\
\text { indices }\end{array}$ & $\begin{array}{l}\text { Cutoff } \\
\text { value (\%) }\end{array}$ \\
\hline 1 & Michard and colleagues [23] & 2000 & 8 to 12 & NA & No & NA & No & $6 \% \mathrm{HES}$ & $500 \mathrm{ml}$ & 30 & $\mathrm{Cl}$ & PAC & 15 \\
\hline 2 & Kramer and colleagues [24] & 2004 & 8 to 10 & NA & No & NA & No & Blood & $500 \mathrm{ml}$ & 10 to 15 & $\mathrm{CO}$ & PAC & 12 \\
\hline 3 & Feissel and colleagues [25] & 2005 & 8 to 10 & NA & No & NA & No & $6 \%$ HES & $7 \mathrm{ml} / \mathrm{kg}$ & 30 & $\mathrm{Cl}$ & Echo & 15 \\
\hline 4 & Charron and colleagues [26] & 2006 & 6 to 10 & NA & No & 14 to 20 & No & $6 \% \mathrm{HES}$ & $100 \mathrm{ml}$ & 1 & SV & Echo & 15 \\
\hline 5 & Monnet and colleagues [27] & 2006 & NA & NA & No & $23 \pm 5$ & No & Saline & $500 \mathrm{ml}$ & 10 & $\begin{array}{l}\text { Aortic } \\
\text { blood flow }\end{array}$ & $\begin{array}{l}\text { Esophageal } \\
\text { Doppler }\end{array}$ & 15 \\
\hline 6 & Feissel and colleagues [28] & 2007 & 8 to 10 & NA & No & NA & No & $6 \% \mathrm{HES}$ & $8 \mathrm{ml} / \mathrm{kg}$ & 30 & $\mathrm{Cl}$ & Echo & 15 \\
\hline 7 & Wyffels and colleagues [29] & 2007 & 8 to 10 & NA & No & NA & No & $6 \% \mathrm{HES}$ & $500 \mathrm{ml}$ & 20 & $\mathrm{CO}$ & PAC & 15 \\
\hline 8 & Auler and colleagues [30] & 2008 & 8 & NA & No & NA & No & LR & $20 \mathrm{ml} / \mathrm{kg}$ & 20 & $\mathrm{Cl}$ & PAC & 15 \\
\hline 9 & $\begin{array}{l}\text { Monge Garcia and } \\
\text { colleagues [31] }\end{array}$ & 2009 & 9 & Ideal & No & 18 to 20 & No & $6 \% \mathrm{HES}$ & $500 \mathrm{ml}$ & 30 & SV & FloTrac & 15 \\
\hline 10 & Vistisen and colleagues [32] & 2009 & $8.1^{\mathrm{a}}$ & Predicted & NA & 14 & No & $6 \% \mathrm{HES}$ & $500 \mathrm{ml}$ & 45 & $\mathrm{Cl}$ & PAC & 15 \\
\hline 11 & Loupec and colleagues [33] & 2011 & 8 to 10 & Predicted & No & NA & No & $6 \% \mathrm{HES}^{\mathrm{b}}$ & $500 \mathrm{ml}$ & 10 & $\mathrm{CO}$ & Echo & 15 \\
\hline 12 & Biais and colleagues [34] & 2012 & 8 to 10 & Predicted & No & $16 \pm 3^{c}$ & No & Saline & $500 \mathrm{ml}$ & 15 & SV & Echo & 15 \\
\hline 13 & Cecconi and colleagues [35] & 2012 & 8 & Ideal & No & 14 & No & Colloid & $250 \mathrm{ml}$ & 5 & $\mathrm{CO}$ & LiDCO plus & 15 \\
\hline 14 & Fellahi and colleagues [36] & 2012 & NA & NA & NA & $12 \pm 2$ & No & $6 \% \mathrm{HES}$ & $500 \mathrm{ml}$ & 15 & $\mathrm{Cl}$ & $\mathrm{PiCCO} 2$ & 15 \\
\hline 15 & $\begin{array}{l}\text { Khwannimit and } \\
\text { colleagues [37] }\end{array}$ & 2012 & $\geq 8$ & NA & No & NA & No & $6 \% \mathrm{HES}$ & $500 \mathrm{ml}$ & 30 & SV & FloTrac & 15 \\
\hline 16 & Monnet and colleagues [38] & 2012 & $8.8^{d}$ & Predicted & No & NA & No & Saline & $500 \mathrm{ml}$ & 20 & $\mathrm{Cl}$ & $\mathrm{PiCCO} 2$ & 15 \\
\hline 17 & Monnet and colleagues [39] & 2012 & $8.5^{\mathrm{e}}$ & Predicted & No & NA & No & Saline & $500 \mathrm{ml}$ & 30 & $\mathrm{Cl}$ & $\mathrm{PiCCO} 2$ & 15 \\
\hline 18 & Yazigi and colleagues [40] & 2012 & 8 & NA & No & 12 & No & $6 \% \mathrm{HES}$ & $7 \mathrm{ml} / \mathrm{kg}$ & 20 & SV & PAC & 15 \\
\hline 19 & Fischer and colleagues [41] & 2013 & 8.6 & NA & NA & $N A^{f}$ & No & $6 \% \mathrm{HES}$ & $500 \mathrm{ml}$ & 15 & $\mathrm{Cl}$ & $\mathrm{PiCCO} 2$ & 15 \\
\hline 20 & Fischer and colleagues [42] & 2013 & 8.2 & NA & No & $N A^{c}$ & No & $6 \%$ HES & $500 \mathrm{ml}$ & 15 & $\mathrm{Cl}$ & $\mathrm{PiCCO} 2$ & 15 \\
\hline 21 & Ishihara and colleagues [43] & 2013 & $\geq 8$ & Ideal & No & 12 to 15 & No & $10 \%$ dextran & $250 \mathrm{ml}$ & 20 & $\mathrm{Cl}$ & PiCCO & 15 \\
\hline 22 & Monnet and colleagues [44] & 2013 & 9 & Predicted & No & NA & No & Saline & $500 \mathrm{ml}$ & 30 & $\mathrm{Cl}$ & $\mathrm{PiCCO} 2$ & 15 \\
\hline
\end{tabular}

$\mathrm{Cl}$, cardiac index; $\mathrm{CO}$, cardiac output; Echo, echocardiography; HES, hydroxyethyl starch; LR, Ringer's lactate; NA, not available; PAC, pulmonary artery catheter; SV, stroke volume; Vt, tidal volume. ${ }^{2} \mathrm{Mean} \mathrm{Vt}$ of $6.9 \mathrm{ml} / \mathrm{kg}$ actual body weight. ${ }^{b}$ Some patients evaluated with passive leg raising test. ${ }^{C}$ Heart rate/respiratory rate $>3.6$. ${ }^{d}$ Only mean $\mathrm{Vt}>8 \mathrm{ml} / \mathrm{kg}$ included. ${ }^{\mathrm{e}}$ Mean $\mathrm{Vt}$ of $7.4 \mathrm{ml} / \mathrm{kg}$ for nonresponder. ${ }^{\mathrm{f}} \mathrm{Heart}$ rate/respiratory rate $=5.7$. 
Table 3 Diagnostic performance of pulse pressure variation from included studies

\begin{tabular}{|c|c|c|c|c|c|c|c|c|c|c|}
\hline Order & Authors & Year & Threshold $^{\mathrm{a}}(\%)$ & tp & $\mathrm{fp}$ & fn & tn & Sens. (\%) & Spec. (\%) & Method used to measure PPV \\
\hline 1 & Michard and colleagues [23] & 2000 & 13 & 15 & 1 & 1 & 23 & 94 & 96 & $\begin{array}{l}\text { Waveform analysis with } \\
\text { computer software }\end{array}$ \\
\hline 2 & Kramer and colleagues [24] & 2004 & 11 & 6 & 1 & 0 & 14 & 100 & 93 & $\begin{array}{l}\text { Waveform analysis with } \\
\text { computer software }\end{array}$ \\
\hline 3 & Feissel and colleagues [25] & 2005 & 17 & 11 & 0 & 2 & 9 & 85 & 100 & $\begin{array}{l}\text { Waveform analysis with } \\
\text { computer software }\end{array}$ \\
\hline 4 & Charron and colleagues [26] & 2006 & 10 & 8 & 2 & 1 & 10 & 89 & 83 & $\begin{array}{l}\text { Waveform analysis with } \\
\text { computer software }\end{array}$ \\
\hline 5 & Monnet and colleagues [27] & 2006 & 12 & 14 & 1 & 2 & 13 & 88 & 93 & $\begin{array}{l}\text { Waveform analysis with } \\
\text { computer software }\end{array}$ \\
\hline 6 & Feissel and colleagues [28] & 2007 & 12 & 18 & 1 & 0 & 9 & 100 & 94 & $\begin{array}{l}\text { Waveform analysis with } \\
\text { computer software }\end{array}$ \\
\hline 7 & Wyffels and colleagues [29] & 2007 & 11.3 & 19 & 1 & 1 & 11 & 95 & 92 & Analysis of printout curves \\
\hline 8 & Auler and colleagues [30] & 2008 & 12 & 38 & 1 & 1 & 19 & 97 & 95 & $\begin{array}{l}\text { Waveform analysis with } \\
\text { computer software }\end{array}$ \\
\hline 9 & Monge Garcia and colleagues [31] & 2009 & 10 & 18 & 1 & 1 & 18 & 95 & 95 & $\begin{array}{l}\text { Waveform analysis with } \\
\text { computer software }\end{array}$ \\
\hline 10 & Vistisen and colleagues [32] & 2009 & 6.5 & 16 & 1 & 1 & 5 & 94 & 83 & $\begin{array}{l}\text { Waveform analysis with } \\
\text { computer software }\end{array}$ \\
\hline 11 & Loupec and colleagues [33] & 2011 & 13 & 19 & 2 & 2 & 17 & 90 & 89 & $\begin{array}{l}\text { Waveform analysis with } \\
\text { computer software }\end{array}$ \\
\hline 12 & Biais and colleagues [34] & 2012 & 10 & 17 & 2 & 2 & 14 & 89 & 88 & $\begin{array}{l}\text { Waveform analysis with } \\
\text { computer software }\end{array}$ \\
\hline 13 & Cecconi and colleagues [35] & 2012 & 13 & 10 & 5 & 2 & 14 & 83 & 74 & Waveform analysis with LiDCO \\
\hline 14 & Fellahi and colleagues [36] & 2012 & 10 & 17 & 1 & 4 & 3 & 81 & 75 & Waveform analysis with PiCCO \\
\hline 15 & Khwannimit and colleagues [37] & 2012 & 12 & 20 & 3 & 4 & 15 & 83 & 83 & $\begin{array}{l}\text { Direct analysis of monitored } \\
\text { arterial tracing }\end{array}$ \\
\hline 16 & Monnet and colleagues [38] & 2012 & 12 & 13 & 0 & 2 & 11 & 85 & 100 & Waveform analysis with PiCCO \\
\hline 17 & Monnet and colleagues [39] & 2012 & 10 & 15 & 2 & 2 & 20 & 88 & 91 & Waveform analysis with PiCCO \\
\hline 18 & Yazigi and colleagues [40] & 2012 & 11.5 & 33 & 5 & 8 & 14 & 80 & 74 & $\begin{array}{l}\text { Direct analysis of monitored } \\
\text { arterial tracing }\end{array}$ \\
\hline 19 & Fischer and colleagues [41] & 2013 & 16 & 12 & 0 & 15 & 10 & 44 & 100 & Waveform analysis with PiCCO \\
\hline 20 & Fischer and colleagues [42] & 2013 & 14 & 36 & 5 & 21 & 18 & 64 & 78 & Waveform analysis with PiCCO \\
\hline 21 & Ishihara and colleagues [43] & 2013 & 8.5 & 11 & 6 & 12 & 14 & 50 & 71 & Waveform analysis with PiCCO \\
\hline 22 & Monnet and colleagues [44] & 2013 & 15 & 14 & 1 & 1 & 19 & 93 & 95 & Waveform analysis with PiCCO \\
\hline
\end{tabular}

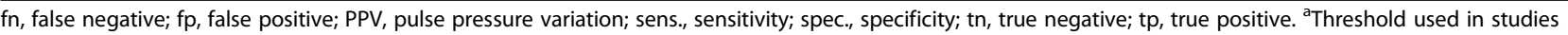
to achieve corresponding sensitivity and specificity.

with tidal volume $>8 \mathrm{ml} / \mathrm{kg}$ is an accurate predictor of fluid responsiveness in critically ill patients, with sensitivity of $0.88(95 \% \mathrm{CI}=0.81$ to 0.92$)$, specificity of $0.89(95 \%$ $\mathrm{CI}=0.84$ to 0.92), and SROC AUC of $0.94(95 \% \mathrm{CI}=0.91$ to 0.95 ).

In a meta-analysis of the literature to determine the ability of PPV, systolic pressure variation, and SVV to predict fluid responsiveness, Marik and colleagues included 29 studies enrolling a total of 685 patients and reported the pooled ROC AUC for PPV as $0.94(95 \% \mathrm{CI}=0.93$ to 0.95$)$ [11], which is in accordance with our findings. Very recently, Hong and colleagues published another metaanalysis involving 865 mechanically ventilated patients from 19 studies, to evaluate the value of both SVV and
PPV in predicting fluid responsiveness [45]. These authors reported a significantly lower pooled ROC AUC for PPV $(0.88,95 \% \mathrm{CI}=0.84$ to 0.92$)$. However, there are several major differences between these two meta-analyses and our study. First, most of the included studies in the above two meta-analyses (12 out of 18 studies [11] and 12 out of 19 studies [45], respectively) were conducted in perioperative settings (that is, before or after induction of anesthesia) or during surgery. In contrast, we limited our metaanalysis to those studies in critically ill patients in the ICU. Perioperative patients differ from critically ill patients in the ICU with regards to age, comorbidities, severity of illness, complications, and clinical outcome. Moreover, the predictive ability of PPV might be compromised in open 


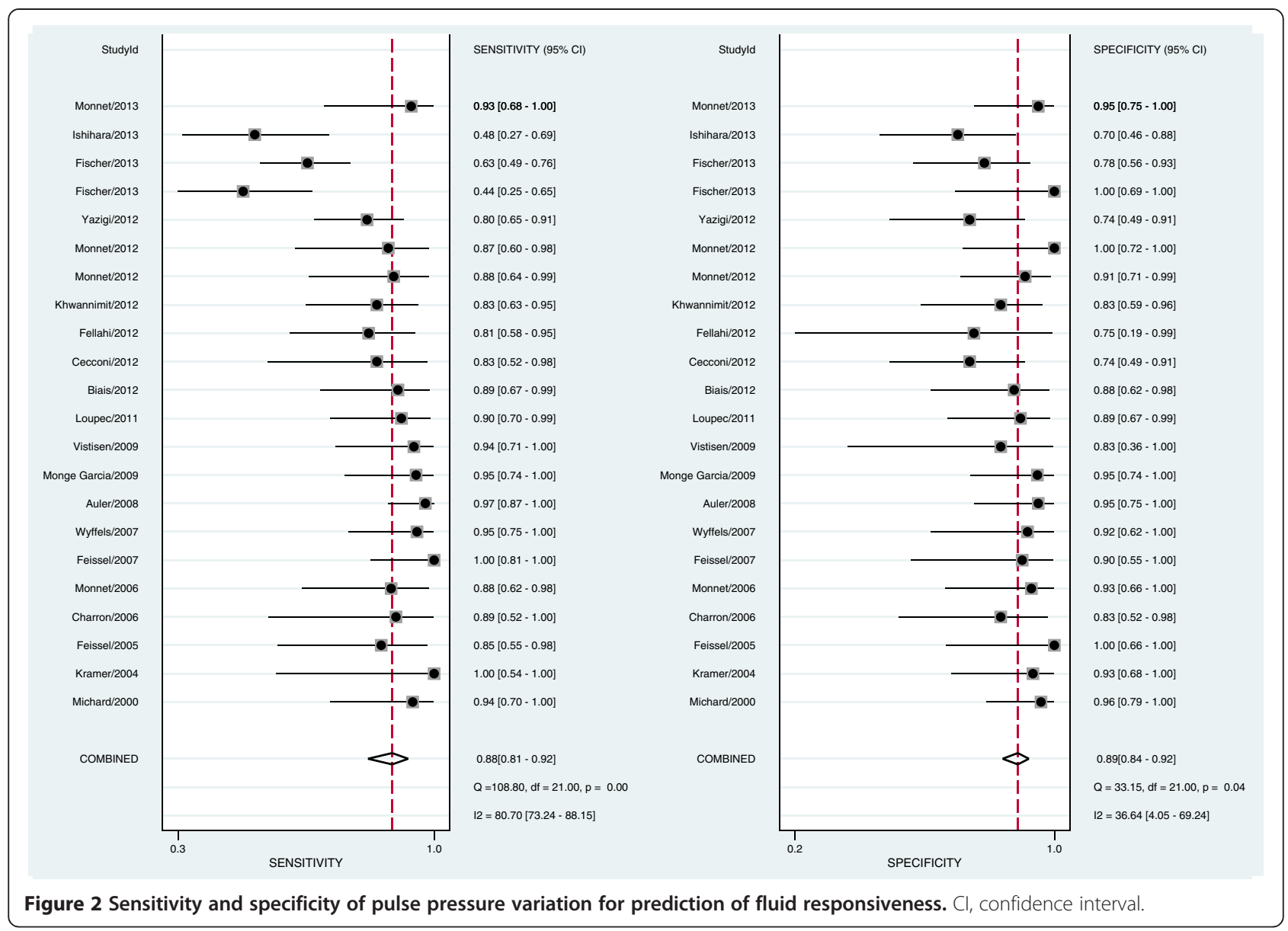

chest conditions, due to inaccurate reflection of phasic changes in preload (and hence stroke volume), increased aortic impedance (and subsequent changes in the relationship between stroke volume and pulse pressure), as well as less pronounced cyclic changes in intrathoracic pressure $[41,46]$. Second, we adopted very strict inclusion and exclusion criteria in our meta-analysis. We excluded studies with a tidal volume $<8 \mathrm{ml} / \mathrm{kg}$. But one study [47] from Marik and colleagues' review and one study [48] from Hong and colleagues' review included tidal volume $<7 \mathrm{ml} /$ $\mathrm{kg}$. We excluded two studies $[49,50]$ included by Marik and colleagues because they reported PPV in fewer than 10 patients so that the $2 \times 2$ contingency table could not be generated. In addition, two studies with contradicting information without clarification from the authors were also excluded [51,52]. Third, Marik and colleagues did not find any heterogeneity using the Cochran $Q$ statistic. Despite the fact that two parameters were meta-analyzed with only one Cochran's $Q$ statistic reported, Hong and colleagues considered between-study heterogeneity low enough to consider the study population as statistically homogeneous for applying appropriate AUC statistics. We reported borderline heterogeneity in our studies. Possible reasons might include the different studies involved in the meta-analysis (as mentioned above) as well as different statistical models used. We found that the heterogeneity observed in our meta-analysis could be fully explained by the threshold effect, which had not been investigated in the previous meta-analyses. The threshold effect is one of main causes of heterogeneity in test accuracy studies. It arises owing to different thresholds or cutoff values used in different studies to determine a positive (or negative) test result. The median threshold level for PPV to predict fluid responsiveness in our meta-analysis was $12 \%$ (interquartile range 10 to $13 \%$ ) with a sensitivity of 0.88 and a specificity of 0.89 . The bottom line is that we believe it would be reasonable to postulate that PPV $>13 \%$ implied fluid responsiveness, while PPV $<10 \%$ indicated fluid unresponsiveness.

To explore other potential sources of heterogeneity, we focused on the studies with the lowest sensitivity value and Youden index (sensitivity + specificity -1 ) (Figure 3). These were also three of the four studies identified using a Galbraith plot (Figure 4). Two of the studies were carried out similarly by the same first author [41,42]. In the study with larger sample size, Fischer and colleagues found that one-third of the patients had right ventricular dysfunction and $34 \%$ of ICU patients with PPV $>12 \%$ were fluid 


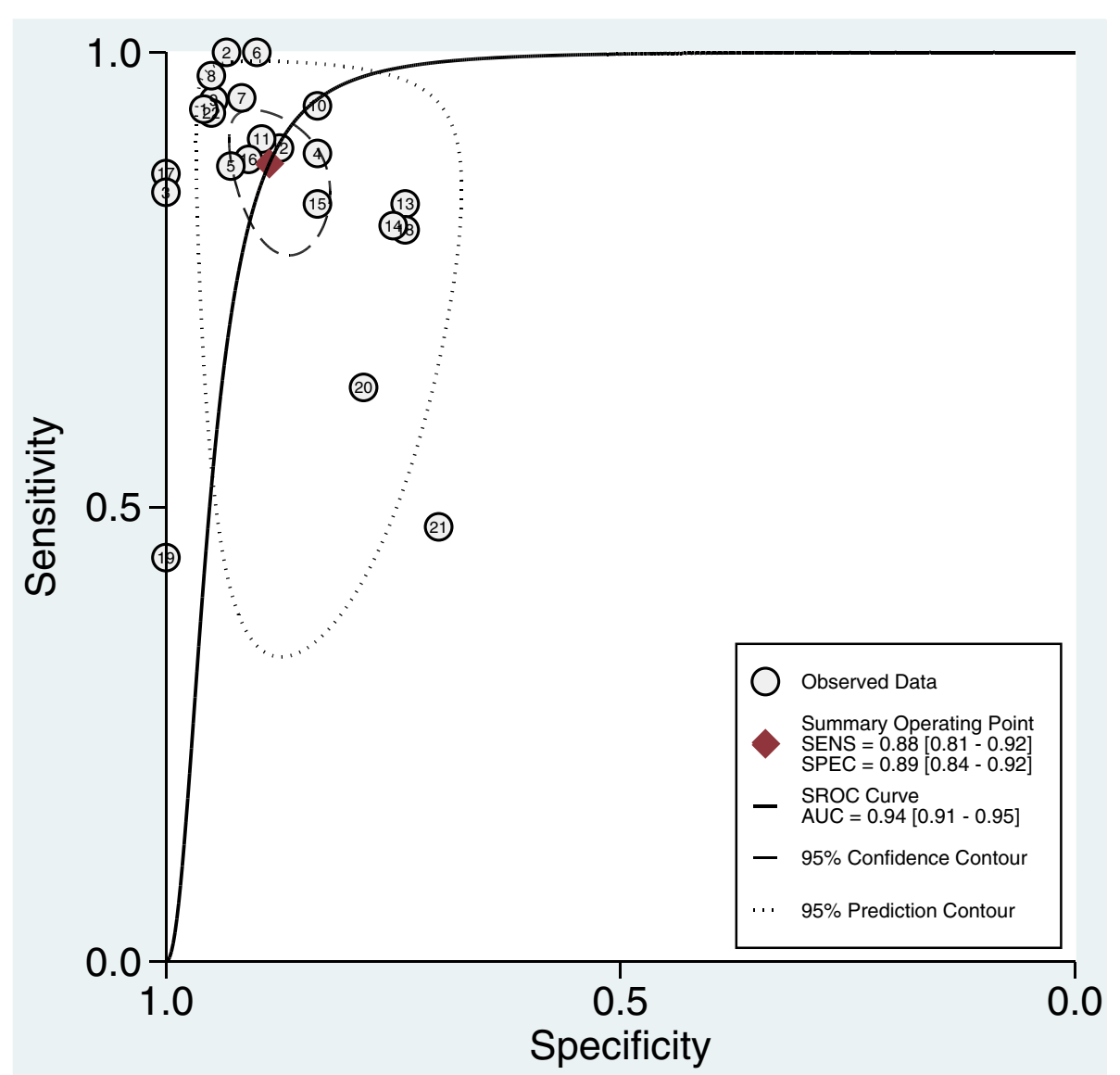

Figure 3 Summary receiver operating characteristic curve. AUC, area under the curve; SENS, sensitivity; SPEC, specificity; SROC, summary receiver operating characteristic.

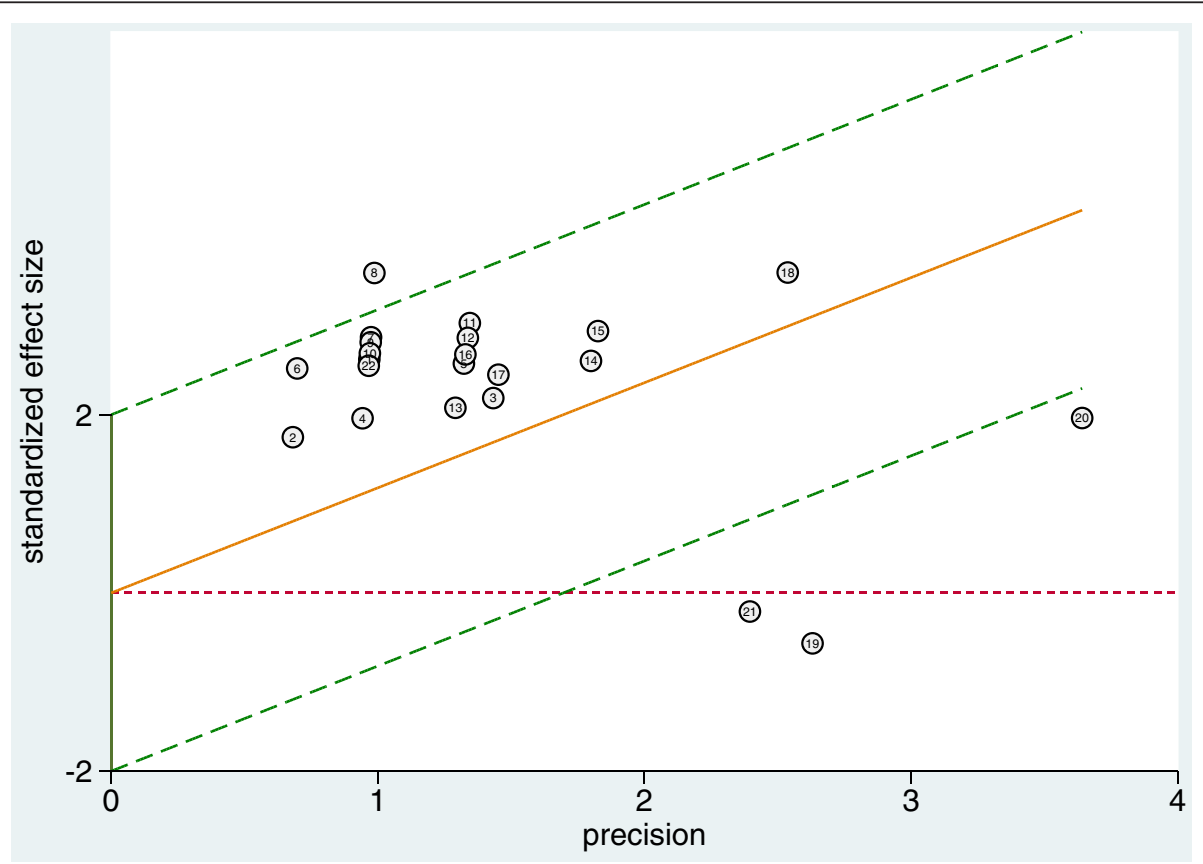

Figure 4 Outliers identified using a Galbraith plot. 


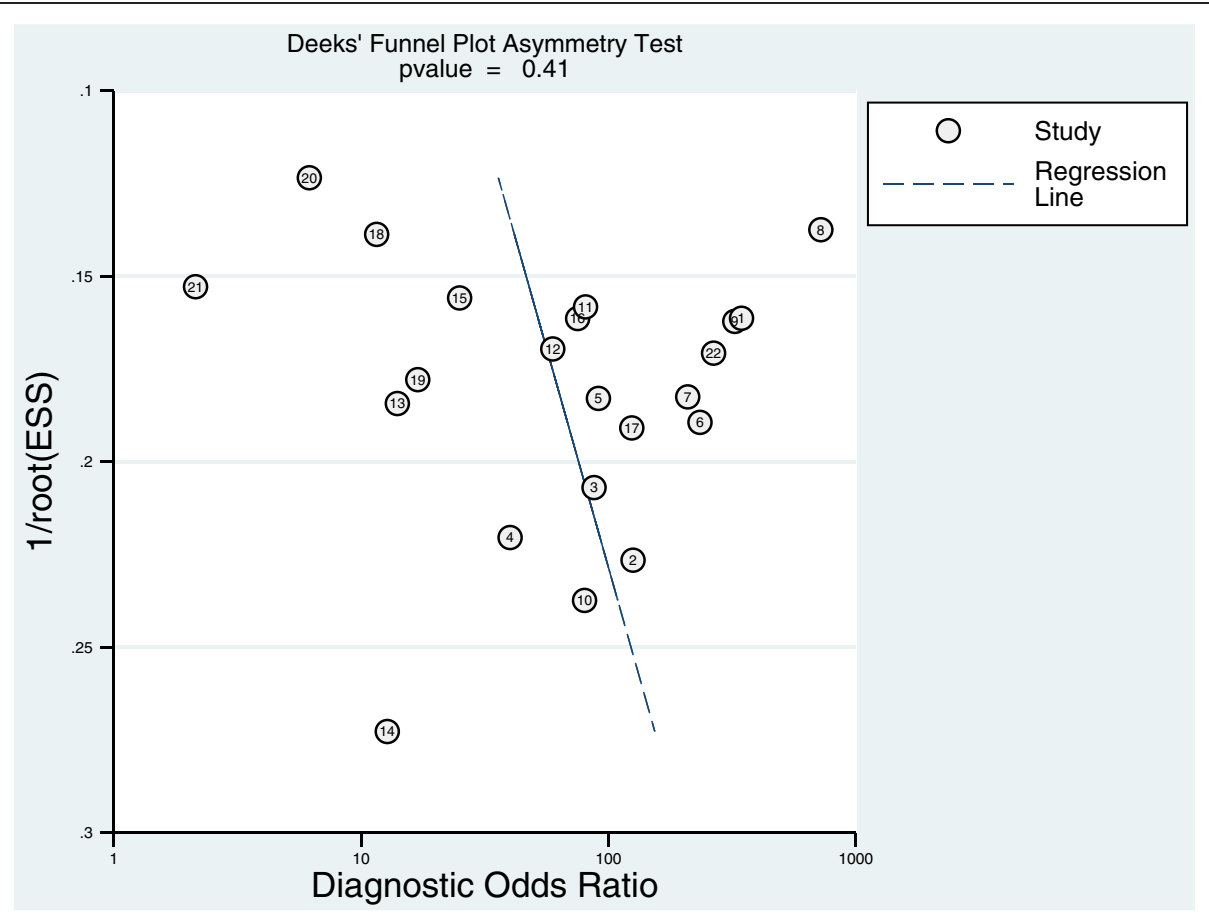

Figure 5 Deeks' funnel plot with superimposed regression line. $P$ value for slope coefficient is 0.41 , which is greater than 0.05 , suggesting the symmetry of the studies and the low likelihood of publication bias.

unresponsive [42]. Wyler von Ballmoos and colleagues supported that right ventricular dysfunction led to poor response to fluids in patients with increased pulmonary artery pressure [53]. Similar to Fischer and colleagues' study, Biais and colleagues evaluated right ventricular function using echocardiography and excluded patients with right ventricular dysfunction from their study [34]. Ishihara and colleagues examined the predictive value of PPV in patients after open-chest abdominothoracic esophagectomy with extensive resection of lymph nodes [43]. They postulated that extensive alteration of thoracic structure might change the cyclic variation of intrathoracic pressure, leading to a modified heart-lung interaction. Postoperative left pleural effusion was common in their patients. Right ventricular dysfunction and extensive alteration of thoracic structure will limit the use of PPV to predict fluid responsiveness.

In the OPTIMISE study, patients in the cardiac output-guided hemodynamic therapy algorithm group were given fluid challenges to reach maximal stroke volume, but no difference of a composite outcome of complications or 30-day mortality was found between the trial group and the usual care group in patients undergoing major gastrointestinal surgery [6]. The POEMAS Study found similar results [54]. However, fluid responsiveness does not necessarily mean that the patients require fluid resuscitation, as long as there are no signs of tissue hypoperfusion [55]. The cardiac functions of critically ill patients and their disease status are dynamic, while the adequacy of tissue perfusion should be the focus [56].

Our study is subject to some limitations. First, sample sizes of the included studies were small. However, even under this condition a meta-analysis still provides valuable information on the diagnostic accuracy until proven otherwise by larger or better-conducted studies [57]. Second, different instruments (pulmonary artery catheter, echocardiography, PiCCO, and so forth) and indices (cardiac output/index, stroke volume, and so forth) were used to evaluate fluid responsiveness, and different methods were used to measure PPV. Nonetheless, this reflects the real situation in a contemporary ICU. It is also convenient to evaluate PPV by directly analyzing monitored arterial tracing or printout curves $[29,37,40]$, which means PPV can be evaluated repeatedly and regularly, and with computer software and waveform analysis can be monitored continuously. This is attractive to intensivists who have to titrate fluid resuscitation in mechanically ventilated patients almost every day. Nevertheless, it is important that elimination or minimization of fluid responsiveness, including PPV, should never be the only goal of fluid therapy. Third, we excluded studies in which patients were ventilated using low tidal volumes, which is the commonly accepted ventilation strategy in patients with acute respiratory distress syndrome. Because most studies showed that although better than conventional static parameters, PPV had limited value in predicting fluid responsiveness in these patients $[52,58-64]$. This was probably because, 


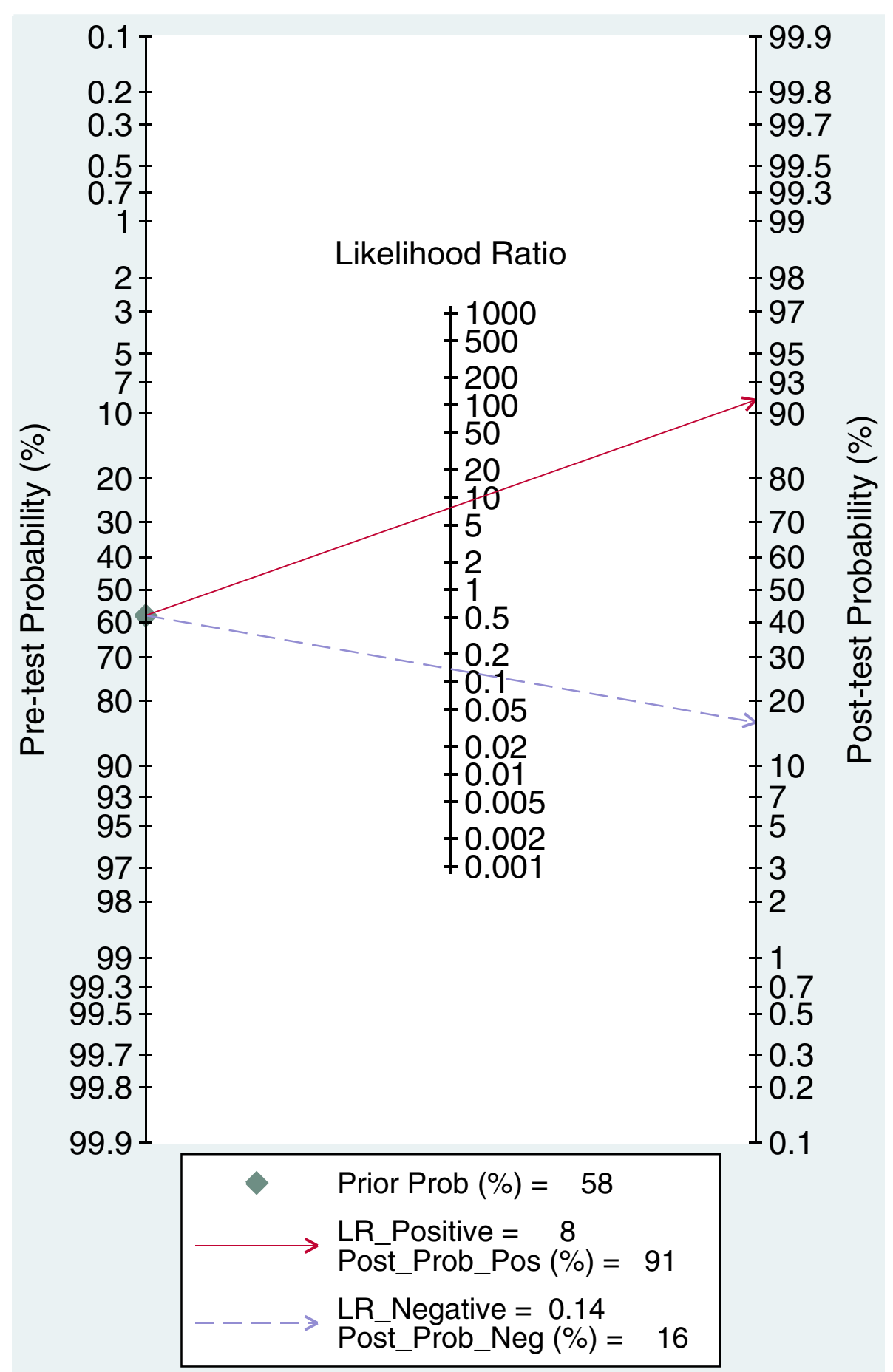

Figure 6 Bayes nomogram of pulse pressure variation for prediction of fluid responsiveness.

with low tidal volume ventilation, the cyclic changes in intrathoracic pressures were not significant enough to induce preload variations [58]. Huang and colleagues and Freitas and colleagues, however, found that PPV accurately predicted fluid responsiveness in patients ventilated with a tidal volume of $6 \mathrm{ml} / \mathrm{kg}[65,66]$. They attributed the discrepancy to higher positive end-expiratory pressure levels, which enhanced the cyclic changes in pleural pressures. More trials concerning the effect of positive end-expiratory pressure on PPV are needed in the future. Before more data are presented, a temporary change of ventilator parameters maybe used to evaluate 
PPV at a larger tidal volume, as demonstrated by Freitas and colleagues [66]. Fourth, more than one-half of the included studies used HES. Nowadays, however, fewer patients receive HES with consideration of its detrimental effect on the kidney, as in the OPTIMISE study [6]. However, we performed a subgroup analysis and found that the SROC AUC of PPV was $0.92(95 \% \mathrm{CI}=0.89$ to 0.94$)$ for studies using HES and $0.96(95 \% \mathrm{CI}=0.94$ to 0.98$)$ for studies using saline, suggesting that the choice of fluid does not influence the predictive value of PPV. Fifth, ICU patients are often with conditions precluding the use of PPV. In their 1-day prospective observational study, Mahjoub and colleagues found that only 15 out of 79 (19\%) patients used PPV to measure fluid responsiveness [67]. However, as advocated by Teboul and Monnet, other fluid responsiveness tests, such as passive leg raising test or end-expiratory occlusion test, could be used when PPV was not available [68]. Measurement of SVV is also influenced, as that of PPV, by the presence of cardiac arrhythmia or spontaneous breathing, as well as low tidal volume ventilation, while it requires much more complicated devices than PPV. Two meta-analyses suggested that both SVV and PPV are accurate predictors of fluid responsiveness in hemodynamically unstable patients under controlled mechanical ventilation $[11,45]$. With studies reporting both PPV and SVV included in our metaanalysis, we found similar results. Sixth, only Biais and colleagues and Fischer and colleagues evaluated right ventricular function using echocardiography, and only Biais and colleagues excluded patients with right ventricular dysfunction from their study $[34,42]$.

\section{Conclusions}

PPV is an accurate predictor of fluid responsiveness in critically ill patients passively ventilated with tidal volume $>8 \mathrm{ml} / \mathrm{kg}$ and without cardiac arrhythmia.

\section{Key messages}

- A significant threshold effect existed while using PPV to determine a responder (or nonresponder) to volume expansion.

- PPV is an accurate predictor of fluid responsiveness in critically ill patients ventilated with relative large tidal volume and without spontaneous breathing and cardiac arrhythmia.

\section{Additional files}

Additional file 1: Table S1. Presenting a summary of QUADAS-2 quality assessment. We tailored QUADAS-2 to our review by omitting the second signalling question in domain $2^{\prime}$ : If a threshold was used, was it pre-specified?'. Reasons for classifying high risk or unclear risk of bias are provided in footnotes for each study.
Additional file 2: Table S2. Presenting the diagnostic performance of PPV and SW from included studies reporting both parameters.

\section{Abbreviations}

AUC: area under the curve; Cl: confidence interval; HES: hydroxyethyl starch; PPV: pulse pressure variation; QUADAS: Quality Assessment of Diagnostic Accuracy included in Systematic Reviews; SROC: summary receiver operating characteristic; SW: stroke volume variation.

\section{Competing interests}

The authors declare that they have no competing interests.

\section{Authors' contributions}

XY planned, performed the literature review and meta-analysis, and wrote the manuscript. BD planned, performed the literature review and meta-analysis, and wrote the manuscript. Both authors read and approved the final manuscript.

Received: 29 June 2014 Accepted: 6 November 2014

Published online: 27 November 2014

\section{References}

1. Marik PE, Monnet $X$, Teboul JL: Hemodynamic parameters to guide fluid therapy. Ann Intensive Care 2011, 1:1.

2. Sakr Y, Vincent JL, Reinhart K, Groeneveld J, Michalopoulos A, Sprung CL, Artigas A, Ranieri VM, Sepsis Occurence in Acutely III Patients Investigators: High tidal volume and positive fluid balance are associated with worse outcome in acute lung injury. Chest 2005, 128:3098-3108.

3. National Heart Lung, and Blood Institute Acute Respiratory Distress Syndrome (ARDS) Clinical Trials Network: Comparison of two fluidmanagement strategies in acute lung injury. N Engl J Med 2006, 354:2564-2575.

4. Murphy CV, Schramm GE, Doherty JA, Reichley RM, Gajic O, Afessa B, Micek ST, Kollef MH: The importance of fluid management in acute lung injury secondary to septic shock. Chest 2009, 136:102-109.

5. Rivers E, Nguyen B, Havstad S, Ressler J, Muzzin A, Knoblich B, Peterson E, Tomlanovich M: Early goal-directed therapy in the treatment of severe sepsis and septic shock. N Engl J Med 2001, 345:1368-1377.

6. Pearse RM, Harrison DA, MacDonald N, Gillies MA, Blunt M, Ackland G, Grocott MP, Ahern A, Griggs K, Scott R, Hinds C, Rowan K, Group OS: Effect of a perioperative, cardiac output-guided hemodynamic therapy algorithm on outcomes following major gastrointestinal surgery: a randomized clinical trial and systematic review. JAMA 2014, 311:2181-2190

7. Michard F, Teboul JL: Predicting fluid responsiveness in ICU patients: a critical analysis of the evidence. Chest 2002, 121:2000-2008.

8. Vincent JL, Weil MH: Fluid challenge revisited. Crit Care Med 2006, 34:1333-1337.

9. Marik PE: Techniques for assessment of intravascular volume in critically ill patients. J Intensive Care Med 2009, 24:329-337.

10. Umbrello M, Formenti P, Galimberti A, Curti M, Zaniboni M, lapichino G: On-line measurement of systolic pressure variation and pulse pressure variation on a multiparametric monitor. Intensive Care Med 2008, 34:386-387.

11. Marik PE, Cavallazzi R, Vasu T, Hirani A: Dynamic changes in arterial waveform derived variables and fluid responsiveness in mechanically ventilated patients: a systematic review of the literature. Crit Care Med 2009, 37:2642-2647.

12. EMBASE [http://www.embase.com/]

13. Whiting PF, Rutjes AW, Westwood ME, Mallett S, Deeks JJ, Reitsma JB, Leeflang MM, Sterne JA, Bossuyt PM, QUADAS-2 Group: QUADAS-2: a revised tool for the quality assessment of diagnostic accuracy studies. Ann Intern Med 2011, 155:529-536.

14. Whiting P, Rutjes AW, Reitsma JB, Bossuyt PM, Kleijnen J: The development of QUADAS: a tool for the quality assessment of studies of diagnostic accuracy included in systematic reviews. BMC Med Res Methodol 2003, 3:25-28.

15. Whiting $\mathrm{P}$, Harbord R, Kleijnen $\mathrm{J}$ : No role for quality scores in systematic reviews of diagnostic accuracy studies. BMC Med Res Methodol 2005, 5:19. 
16. Riley RD, Abrams KR, Lambert PC, Sutton AJ, Thompson JR: An evaluation of bivariate random-effects meta-analysis for the joint synthesis of two correlated outcomes. Stat Med 2007, 26:78-97.

17. Riley RD, Abrams KR, Sutton AJ, Lambert PC, Thompson JR: Bivariate random-effects meta-analysis and the estimation of between-study correlation. BMC Med Res Methodol 2007, 7:3.

18. Riley RD, Thompson JR, Abrams KR: An alternative model for bivariate random-effects meta-analysis when the within-study correlations are unknown. Biostatistics 2008, 9:172-186.

19. Dahabreh IJ, Trikalinos TA, Lau J, Schmid C: An Empirical Assessment of Bivariate Methods for Meta-analysis of Test Accuracy. Rockville, MD: Agency for Healthcare Research and Quality (US); 2012. [http://www.ncbi.nlm.nih. gov/books/NBK115736/]

20. Higgins JP, Thompson SG, Deeks JJ, Altman DG: Measuring inconsistency in meta-analysis. BMJ 2003, 327:557-560.

21. Moses LE, Shapiro D, Littenberg B: Combining independent studies of a diagnostic test into a summary ROC curve: data-analytic approaches and some additional considerations. Stat Med 1993, 12:1293-1316.

22. Deeks JJ, Macaskill P, Irwig L: The performance of tests of publication bias and other sample size effects in systematic reviews of diagnostic test accuracy was assessed. J Clin Epidemiol 2005, 58:882-893.

23. Michard F, Boussat S, Chemla D, Anguel N, Mercat A, Lecarpentier Y, Richard C, Pinsky MR, Teboul JL: Relation between respiratory changes in arterial pulse pressure and fluid responsiveness in septic patients with acute circulatory failure. Am J Respir Crit Care Med 2000, 162:134-138.

24. Kramer A, Zygun D, Hawes H, Easton P, Ferland A: Pulse pressure variation predicts fluid responsiveness following coronary artery bypass surgery. Chest 2004, 126:1563-1568.

25. Feissel M, Badie J, Merlani PG, Faller JP, Bendjelid K: Pre-ejection period variations predict the fluid responsiveness of septic ventilated patients. Crit Care Med 2005, 33:2534-2539.

26. Charron C, Fessenmeyer C, Cosson C, Mazoit JX, Hebert JL, Benhamou D, Edouard AR: The influence of tidal volume on the dynamic variables of fluid responsiveness in critically ill patients. Anesth Analg 2006, 102:1511-1517.

27. Monnet X, Rienzo M, Osman D, Anguel N, Richard C, Pinsky MR, Teboul JL: Passive leg raising predicts fluid responsiveness in the critically ill. Crit Care Med 2006, 34:1402-1407.

28. Feissel M, Teboul JL, Merlani P, Badie J, Faller JP, Bendjelid K: Plethysmographic dynamic indices predict fluid responsiveness in septic ventilated patients. Intensive Care Med 2007, 33:993-999.

29. Wyffels PAH, Durnez PJ, Helderweirt J, Stockman WM, De Kegel D: Ventilation-induced plethysmographic variations predict fluid responsiveness in ventilated postoperative cardiac surgery patients. Anesth Analg 2007, 105:448-452.

30. Auler JO Jr, Galas F, Hajjar L, Santos L, Carvalho T, Michard F: Online monitoring of pulse pressure variation to guide fluid therapy after cardiac surgery. Anesth Analg 2008, 106:1201-1206.

31. Monge Garcia MI, Gil Cano A, Diaz Monrové JC: Brachial artery peak velocity variation to predict fluid responsiveness in mechanically ventilated patients. Crit Care 2009, 13:R142.

32. Vistisen ST, Struijk JJ, Larsson A: Automated pre-ejection period variation indexed to tidal volume predicts fluid responsiveness after cardiac surgery. Acta Anaesthesiol Scand 2009, 53:534-542.

33. Loupec T, Nanadoumgar H, Frasca D, Petitpas F, Laksiri L, Baudouin D, Debaene B, Dahyot-Fizelier C, Mimoz O: Pleth variability index predicts fluid responsiveness in critically ill patients. Crit Care Med 2011, 39:294-299.

34. Biais M, Cottenceau V, Stecken L, Jean M, Ottolenghi L, Roullet S, Quinart A Sztark F: Evaluation of stroke volume variations obtained with the pressure recording analytic method. Crit Care Med 2012, 40:1186-1191.

35. Cecconi M, Monti G, Hamilton MA, Puntis M, Dawson D, Tuccillo ML, Della Rocca G, Grounds RM, Rhodes A: Efficacy of functional hemodynamic parameters in predicting fluid responsiveness with pulse power analysis in surgical patients. Minerva Anestesiol 2012, 78:527-533.

36. Fellahi JL, Fischer MO, Rebet $\mathrm{O}$, Massetti M, Gérard JL, Hanouz JL: A comparison of endotracheal bioimpedance cardiography and transpulmonary thermodilution in cardiac surgery patients. $J$ Cardiothorac Vasc Anesth 2012, 26:217-222.

37. Khwannimit B, Bhurayanontachai R: Prediction of fluid responsiveness in septic shock patients: comparing stroke volume variation by FloTrac/
Vigileo and automated pulse pressure variation. Eur J Anaesthesiol 2012, 29:64-69.

38. Monnet X, Bleibtreu A, Ferre A, Dres M, Gharbi R, Richard C, Teboul JL: Passive leg-raising and end-expiratory occlusion tests perform better than pulse pressure variation in patients with low respiratory system compliance. Crit Care Med 2012, 40:152-157.

39. Monnet X, Dres M, Ferre A, Le Teuff G, Jozwiak M, Bleibtreu A, Le Deley MC, Chemla D, Richard C, Teboul JL: Prediction of fluid responsiveness by a continuous non-invasive assessment of arterial pressure in critically ill patients: comparison with four other dynamic indices. Br J Anaesth 2012, 109:330-338.

40. Yazigi A, Khoury E, Hlais S, Madi-Jebara S, Haddad F, Hayek G, Jabbour K: Pulse pressure variation predicts fluid responsiveness in elderly patients after coronary artery bypass graft surgery. J Cardiothorac Vasc Anesth 2012, 26:387-390.

41. Fischer MO, Coucoravas J, Truong J, Zhu L, Gérard JL, Hanouz JL, Fellahi JL: Assessment of changes in cardiac index and fluid responsiveness: a comparison of Nexfin and transpulmonary thermodilution. Acta Anaesthesiol Scand 2013, 57:704-712.

42. Fischer MO, Pelissier A, Bohadana D, Gérard JL, Hanouz JL, Fellahi JL: Prediction of responsiveness to an intravenous fluid challenge in patients after cardiac surgery with cardiopulmonary bypass: a comparison between arterial pulse pressure variation and digital plethysmographic variability index. J Cardiothorac Vasc Anesth 2013, 27:1087-1093.

43. Ishihara H, Hashiba E, Okawa H, Saito J, Kasai T, Tsubo T: Neither dynamic, static, nor volumetric variables can accurately predict fluid responsiveness early after abdominothoracic esophagectomy. Perioper Med (Lond) 2013, 2:3

44. Monnet X, Guérin L, Jozwiak M, Bataille A, Julien F, Richard C, Teboul JL: Pleth variability index in a weak predictor of fluid responsiveness in patients receiving norepinephrine. Br J Anaesth 2013, 110:207-213.

45. Hong JQ, He HF, Chen ZY, Du ZS, Liu WF, Weng PQ, Huang HB: Comparison of stroke volume variation with pulse pressure variation as a diagnostic indicator of fluid responsiveness in mechanically ventilated critically ill patients. Saudi Med J 2014, 35:261-268.

46. Rex S, Schälte G, Schroth S, de Waal EE, Metzelder S, Overbeck Y, Rossaint R, Buhre W: Limitations of arterial pulse pressure variation and left ventricular stroke volume variation in estimating cardiac pre-load during open heart surgery. Acta Anaesthesiol Scand 2007, 51:1258-1267.

47. Wiesenack C, Fiegl C, Keyser A, Prasser C, Keyl C: Assessment of fluid responsiveness in mechanically ventilated cardiac surgical patients. Eur J Anaesthesiol 2005, 22:658-665.

48. Nordstrom J, Hallsjo-Sander C, Shore R, Bjorne H: Stroke volume optimization in elective bowel surgery: a comparison between pulse power wave analysis (LiDCOrapid) and oesophageal Doppler (CardioQ). Br J Anaesth 2013, 110:374-380.

49. Michard F, Chemla D, Richard C, Wysocki M, Pinsky MR, Lecarpentier $Y$ Teboul JL: Clinical use of respiratory changes in arterial pulse pressure to monitor the hemodynamic effects of PEEP. Am J Respir Crit Care Med 1999, 159:935-939.

50. Bendjelid K, Suter PM, Romand JA: The respiratory change in preejection period: a new method to predict fluid responsiveness. J App/ Physiol 2004, 96:37-342.

51. De Backer D, Heenen S, Piagnerelli M, Koch M, Vincent JL: Pulse pressure variations to predict fluid responsiveness: influence of tidal volume. Intensive Care Med 2005, 31:517-523.

52. Vallee F, Richard JCM, Mari A, Gallas T, Arsac E, Verlaan PS, Chousterman B, Samii K, Genestal M, Fourcade O: Pulse pressure variations adjusted by alveolar driving pressure to assess fluid responsiveness. Intensive Care Med 2009, 35:1004-1010.

53. Wyler von Ballmoos M, Takala J, Roeck M, Porta F, Tueller D, Ganter CC, Schroder R, Bracht $\mathrm{H}$, Baenziger B, Jakob SM: Pulse-pressure variation and hemodynamic response in patients with elevated pulmonary artery pressure: a clinical study. Crit Care 2010, 14:R111.

54. Pestana D, Espinosa E, Eden A, Najera D, Collar L, Aldecoa C, Higuera E, Escribano S, Bystritski D, Pascual J, Fernandez-Garijo P, de Prada B, Muriel A Pizov R: Perioperative goal-directed hemodynamic optimization using noninvasive cardiac output monitoring in major abdominal surgery: a prospective, randomized, multicenter, pragmatic trial: POEMAS Study 
(PeriOperative goal-directed thErapy in Major Abdominal Surgery). Anesth Analg 2014, 119:579-587.

55. Antonelli M, Levy M, Andrews PJ, Chastre J, Hudson LD, Manthous C, Meduri GU, Moreno RP, Putensen C, Stewart T, Torres A: Hemodynamic monitoring in shock and implications for management. International Consensus Conference, Paris, France, 27-28 April 2006. Intensive Care Med 2007, 33:575-590.

56. Parker MM: Goals for fluid resuscitation: a real challenge. Crit Care Med 2007, 35:295-296.

57. Deville WL, Buntinx F, Bouter LM, Montori VM, de Vet HC, van der Windt DA, Bezemer PD: Conducting systematic reviews of diagnostic studies: didactic guidelines. BMC Med Res Methodol 2002, 2:9.

58. Oliveira-Costa CD, Friedman G, Vieira SR, Fialkow L: Pulse pressure variation and prediction of fluid responsiveness in patients ventilated with low tidal volumes. Clinics (Sao Paulo) 2012, 67:773-778.

59. Lakhal K, Ehrmann S, Benzekri-Lefevre D, Runge I, Legras A, Dequin P, Mercier E, Wolff M, Regnier B, Boulain T: Respiratory pulse pressure variation fails to predict fluid responsiveness in acute respiratory distress syndrome. Crit Care 2011, 15:R85.

60. Muller L, Louart G, Bousquet PJ, Candela D, Zoric L, de La Coussaye JE, Jaber S, Lefrant JY: The influence of the airway driving pressure on pulsed pressure variation as a predictor of fluid responsiveness. Intensive Care Med 2010, 36:496-503.

61. Muller L, Toumi M, Bousquet PJ, Riu-Poulenc B, Louart G, Candela D, Zoric L, Suehs C, De La Coussaye JE, Molinari N, Lefrant JY: An increase in aortic blood flow after an infusion of $100 \mathrm{ml}$ colloid over 1 minute can predict fluid responsiveness: the mini-fluid challenge study. Anesthesiology 2011, 115:541-547.

62. Lansdorp B, Lemson J, Van Putten MJAM, De Keijzer A, Van Der Hoeven JG, Pickkers P: Dynamic indices do not predict volume responsiveness in routine clinical practice. Br J Anaesth 2012, 108:395-401.

63. Guinot PG, Zogheib E, Detave M, Moubarak M, Hubert V, Badoux L, Bernard $E$, Besserve $P$, Caus T, Dupont H: Passive leg raising can predict fluid responsiveness in patients placed on venovenous extracorporeal membrane oxygenation. Crit Care 2011, 15:R216.

64. Friedman GF, Costa CD, Vieira SR, Fialkow L: The value of pulse pressure variation to predict volume response in patients ventilated with low VT. Crit Care 2010, 14:S41.

65. Huang CC, Fu JY, Hu HC, Kao KC, Chen NH, Hsieh MJ, Tsai YH: Prediction of fluid responsiveness in acute respiratory distress syndrome patients ventilated with low tidal volume and high positive end-expiratory pressure. Crit Care Med 2008, 36:2810-2816.

66. Freitas FGR, Bafi AT, Nascente APM, Assuncao M, Mazza B, Azevedo LCP, Machado FR, Mahajan RP: Predictive value of pulse pressure variation for fluid responsiveness in septic patients using lung-protective ventilation strategies. Br J Anaesth 2012, 110:402-408.

67. Mahjoub Y, Lejeune V, Muller L, Perbet S, Zieleskiewicz L, Bart F, Veber B, Paugam-Burtz C, Jaber S, Ayham A, Zogheib E, Lasocki S, Vieillard-Baron A, Quintard H, Joannes-Boyau O, Plantefeve G, Montravers P, Duperret S, Lakhdari M, Ammenouche N, Lorne E, Slama M, Dupont H: Evaluation of pulse pressure variation validity criteria in critically ill patients: a prospective observational multicentre point-prevalence study. Br J Anaesth 2014, 112:681-685.

68. Teboul JL, Monnet X: Pulse pressure variation and ARDS. Minerva Anestesiol 2013, 79:398-407.

doi:10.1186/s13054-014-0650-6

Cite this article as: Yang and Du: Does pulse pressure variation predict fluid responsiveness in critically ill patients? A systematic review and meta-analysis. Critical Care 2014 18:650.

\section{Submit your next manuscript to BioMed Central and take full advantage of:}

- Convenient online submission

- Thorough peer review

- No space constraints or color figure charges

- Immediate publication on acceptance

- Inclusion in PubMed, CAS, Scopus and Google Scholar

- Research which is freely available for redistribution

Submit your manuscript at www.biomedcentral.com/submit
C Biomed Central 